\title{
WALL STABILIZATION OF HIGH BETA PLASMAS IN DIII-D
}

\author{
by \\ T.S. TAYLOR, E.J. STRAIT, L.L. LAO, M. MAUEL, A.D. TURNBULL, \\ K.H. BURRELL, M.S. CHU, J.R. FERRON, R.J. GROEBNER, R.J. LA HAYE, \\ B.W. RICE, R.T. SNIDER, S.J. THOMPSON, D. WROBLEWSKI, \\ and D.J. LIGHTLY
}

FEBRUARY 1995 


\section{DISCLAIMER}

This report was prepared as an account of work sponsored by an agency of the United States Government. Neither the United States Government nor any agency thereof, nor any of their employees, makes any warranty, express or implied, or assumes any legal liability or responsibility for the accuracy, completeness, or usefulness of any information, apparatus, product, or process disclosed, or represents that its use would not infringe privately owned rights. Reference herein to any specific commercial product, process, or service by trade name, trademark, manufacturer, or otherwise, does not necessarily constitute or imply its endorsement, recommendation, or favoring by the United States Government or any agency thereof. The views and opinions of authors expressed herein do not necessarily state or reflect those of the United States Government or any agency thereof. 


\section{DISCLAIMER}

Portions of this document may be illegible in electronic image products. Images are produced from the best available original document. 


\title{
WALL STABILIZATION OF HIGH BETA PLASMAS IN DIII-D
}

\author{
by \\ T.S. TAYLOR, E.J. STRAIT, L.L. LAO, M. MAUEL, ${ }^{\star}$ A.D. TURNBULL, \\ K.H. BURRELL, M.S. CHU, J.R. FERRON, R.J. GROEBNER, R.J. LA HAYE, \\ B.W. RICE, † R.T. SNIDER, S.J. THOMPSON, D. WROBLEWSKI, † \\ and D.J. LIGHTLY
}

This is a preprint of an invited paper presented at the 36th Annual Meeting of the Division of Plasma Physics, November 7-11, 1994, in Minneapolis, Minnesota, and to be printed in the PHYSICS OF PLASMAS

\begin{abstract}
Work supported by the U.S. Department of Energy under Contract Nos. DE-AC03-89ER51114, W-7405-ENG-48, and DE-AC05-84OR21400
\end{abstract}

*Columbia University.

†Lawrence Livermore National Laboratory.

‡Gustavus Adolphus College.

GA PROJECT 3466 FEBRUARY 1995

DISTRIBUTIOR OF THIS DOCUMENT IS UNLIMITED

TJ GENERAL ATOMICS 


\section{ABSTRACT}

Detailed analysis of recent high beta discharges in the DIII- $\mathrm{D}^{1}$ tokamak demonstrates that the resistive vacuum vessel can provide stabilization of low $\mathbf{n}$ magnetohydrodynamic (MHD) modes. The experimental beta values reaching up to $\beta_{\mathrm{T}}=12.6 \%$ are more than $30 \%$ larger than the maximum stable beta calculated with no wall stabilization. Plasma rotation is essential for stabilization. When the plasma rotation slows sufficiently, unstable modes with the characteristics of the predicted "resistive wall" mode are observed. Through slowing of the plasma rotation between the $q=2$ and $q=3$ surfaces with the application of a non-axisymmetric field, we have determined that the rotation at the outer rational surfaces is most important, and that the critical rotation frequency is of the order of $\Omega / 2 \pi=1 \mathrm{kHz}$. 



\section{CONTENTS}

ABSTRACT iii

I. INTRODUCTION 1

II. THEORETICAL PREDICTIONS 5

II. EXPERIMENTS TO EVALUATE THE STABILIZING INFLUENCE
OFA RESISTIVE WALL

IV. STABILITY ANALYSIS

V. DISCHARGE TERMINATION AND ROTATION 15

VI. DISCUSSION 21

$\begin{array}{lc}\text { REFERENCES } & 23\end{array}$

$\begin{array}{lr}\text { ACKNOWLEDGMENTS } & 29\end{array}$ 


\section{LIST OF FIGURES}

Fig. 1. Temporal evolution of wall stabilized discharge

Fig. 2. Scaling of the DIII-D beta limit with $\ell_{j}$ and normalized current, including the recent high beta experiments

Fig. 3 Calculated ideal kink mode limits

Fig. 4. The temporal evolution of discharge 80111 , showing the correlation between the rotation, and the growth of the unstable mode

Fig. 5. Temporal evolution of two similar discharges, one with large $\mathrm{C}$-coil current, and one with smaller C-coil current 


\section{INTRODUCTION}

The economic viability of a tokamak reactor depends upon the reliable operation with sufficient energy confinement time, $\tau_{\mathrm{E}}$, for ignition margin, and sufficiently high volume average toroidal beta, $\beta_{\mathrm{T}}$, to attain the required fusion power density. Here $\beta_{\mathrm{T}}=\langle\mathrm{p}\rangle \times 2 \mu_{0} / \mathrm{B}_{\mathrm{T}}^{2}$; is the ratio of the volume average plasma pressure to the confining magnetic field. The value of $B_{T}$ used in this manuscript is the vacuum toroidal field at the center of the last closed flux surface, $\mathrm{B}_{\mathrm{T}}=\mathrm{B}_{\mathrm{T}}^{\mathrm{vac}}\left(\mathrm{R}_{\mathrm{GEO}}\right), \mathrm{R}_{\mathrm{GEO}}=\left(\mathrm{R}_{\max }+\mathrm{R}_{\min }\right) / 2$. Although beta values predicted by "Troyon scaling,"2,3 are sufficient for ignition experiments and the design of tokamak power plants, significant reductions in the size and cost of a tokamak power plant can be realized if the maximum operating beta can be increased beyond that given by Troyon scaling. ${ }^{4}$ Recent tokamak experiments routinely obtain energy confinement values which greatly exceed that predicted by low-mode (L-mode) scaling relations, ${ }^{5} \mathrm{H}=\tau_{\mathrm{E}}^{\mathrm{EXP}} / \tau_{\mathrm{E}}^{\mathrm{ITER}-89 \mathrm{P}} \geq 3$, where the ratio of the experimental confinement time to that predicted by the ITER-89P confinement scaling calculation. ${ }^{5}$ In these experimentally achieved improved energy confinement regimes, the ability to increase the fusion power density is no longer limited by transport or heating power but instead by stability at high beta. ${ }^{2}$ To take advantage of these better energy confinement regimes, reliable operation at higher values of beta is thus required.

Although there are a number of techniques to avoid the stability limit imposed by ideal internal modes (ballooning, infernal, and internal kink), ultimately, beta is limited by low $\mathbf{n}$ ideal kink modes. Theory calculations have shown that a nearby, ideal conducting wall can stabilize the external kink. In proposed "advanced tokamak regimes" the calculated stabilization by an ideal conducting wall can increase beta by more than a factor of 2.6,7 For example, the simulated DIII-D second-stable-core very high-mode (VH-mode) equilibria, values of normalized beta, $\beta_{\mathrm{N}}$ $=\beta_{\mathrm{T}}(\mathrm{I} / \mathrm{aB})^{-1} \% \mathrm{~m}-\mathrm{T}-\mathrm{MA}$ as high as $\beta_{\mathrm{N}}=5.7$ are predicted to be stable with a conducting wall 
at the location of the vacuum vessel. In contrast the highest stable $\beta_{\mathrm{N}}$ predicted without conducting a wall is only $\beta_{N}=2.8$. Discharges have been produced in DIII-D with reversed central magnetic shear as proposed in the second stable core $\mathrm{VH}-$ mode. Although $\beta_{\mathrm{T}}$ has not yet been increased sufficiently in these discharges to test the stability limits, good confinement is obtained, $\mathrm{H}=3$, and an internal transport barrier has been observed in the ion temperature profile.

Previous experiments had suggested that beta could exceed the ideal limit calculated without wall stabilization. ${ }^{8-10}$ These experiments claimed a better agreement with ideal theory if the real resistive wall were providing stabilization as if it were an ideal conductor. However, in these experiments, there was a lack of detailed pressure or $q$ profile data, and a significant uncertainty in the value of the safety factor on axis, $q(0)$. Given the known strong dependence of the predicted beta limit on both the $q$ profile and the pressure profile $11-13$ and the ambiguity introduced in the ideal calculations by the presence of the internal kink instability when $q(0)<1$, these early experimental results were not taken as definitive. Furthermore, earlier theory work indicated that a resistive wall would not increase the stability limit against the ideal external kink even in the presence of plasma rotation. ${ }^{14-17}$

However, recent DIII-D experiments ${ }^{18-20}$ have provided convincing evidence of stabilization by a resistive wall. Detailed measurements of the $q$ profile with the motional Stark effect (MSE), 21 have allowed more accurate equilibrium and stability analysis and made it possible to obtain convincing evidence of stabilization by a resistive wall. We have observed beta values $30 \%$ greater than those predicted to be stable against the ideal kink in the absence of an ideal conducting wall for durations longer that 10 wall penetration times. Detailed rotation measurements with the charge exchange recombination spectroscopy (CER), ${ }^{22}$ have allowed us to assess the importance of plasma rotation in the kink stabilization process. We clearly see low $\mathrm{m} / \mathrm{n}$ modes appear, and lead to termination of the high beta phase when the plasma rotation is 
sufficiently slowed. In addition, during the slow plasma rotation, we have observed a mode growing at approximately the resistive wall time scale, consistent with the predictions from recent resistive-wall stabilization theory mode. A six-segment error field correction coil to decrease the existing non-axisymmetric fields, or to produce large non-axisymmetric fields, ${ }^{23}$ has recently been installed on the DIII-D. 23 By using this coil to increase the non-axisymmetric fields and slow the rotation, we have demonstrated the importance of the plasma rotation near the $q=2$ and 3 surfaces.

In the following section, we will briefly discuss the predictions of the recently developed theory that includes both plasma rotation and plasma dissipation. In Section III, we will discuss the experiments performed on DIII-D to evaluate resistive wall stabilization. In Section IV, we discuss the equilibrium reconstruction and stability analyses of two high beta discharges: 80108 with $q(0)<1$ which reached $\beta_{\mathrm{T}}=12.6 \%, \beta_{\mathrm{N}}=4.3$; and 80111 with $q(0)>1$ which reached $\beta_{\mathrm{N}}=$ 3.8. The termination of these discharges and the impact of the toroidal rotation is discussed in Section V. A discussion of these results is included in Section VI. 



\section{THEORETICAL PREDICTIONS}

Until recently, theoretical predictions showed no increase in the stability limit of an ideal plasma with the addition of finite resistivity walls. ${ }^{14-17}$ In the presence of a resistive wall the unstable mode was predicted to have nearly zero real frequency $(\omega \sim 0)$ and grow on the time scale for the mode to penetrate the wall, $\gamma=\tau_{\mathrm{w}}^{-1}$. Recently, it was recognized that dissipation in a rotating plasma surrounded by a resistive wall could result in high stabilization. 24 The prediction of stabilization by dissipation and rotation has been demonstrated in numerical calculations ${ }^{24-26}$ and has also been predicted analytically.

To better understand the experiment, it is instructive to understand the predictions from the theory. We have chosen a form of the dispersion relation that follows that given by Zakharov and Putvinskii 13 and added a term to represent dissipation. The resulting dispersion relation is:

$$
\underbrace{(\gamma+i n \Omega)^{2}-\Gamma_{\infty}^{2}}_{\text {Ideal Stability }}+\underbrace{(\gamma+i n \Omega) \Gamma_{\mathrm{DIS}}}_{\text {Plasma Dissipation }}=\underbrace{\frac{\Gamma_{\infty}^{2}\left(d_{c} / d\right)}{2 d \gamma \tau_{W}+1}}_{\text {Resistive Wall }}
$$

Here the plasma is assumed to rotate uniformly with respect to the wall with rotation frequency $\Omega$, while $\Gamma_{\infty}$ is the ideal growth rate with the wall at infinity, $\Gamma_{\text {DIS }}$ is the dissipation rate, $d=$ $b-a$ is the plasma to wall separation, $d_{c}$ is the separation distance at which an ideal conducting wall is no longer stabilizing, and $\tau_{\mathrm{W}}=\mu_{0} \sigma b \delta$, is the time constant of the wall, where $\sigma$ is the wall conductivity, $b$ is the wall radius, and $\delta$ is the wall thickness. The dispersion relation is written such that the "ideal" terms, the "resistive wall" term and the "dissipation" terms are separable as shown. $d_{c}$ is the critical plasma wall separation for an ideal wall; for $d>d_{c}$, the plasma is ideal unstable and remains unstable as wall resistivity and plasma dissipation are added. When the wall is made resistive, but without plasma dissipation, there is instability at all 
wall positions. For $d<d_{C}$ the mode is stationary with respect to the wall and the unstable mode "penetrates" through the wall with a growth rate of approximately $\gamma=\tau_{\mathrm{w}}^{-1}$ : this mode is often called the "resistive wall mode." When dissipation is added without sufficient plasma rotation, the plasma becomes stable over a narrow range of wall positions with $d$ just less than $d_{c}$. The width of this stable gap in the wall position increases as the plasma dissipation and plasma rotation increases. A resistive wall very close to the plasma is unfavorable for stability.

The general features given by the dispersion relation are reproduced by various models, although the detailed dependencies of $\Gamma_{\text {DIS }}$ on plasma parameters are not yet well understood. A number of dissipation models have been evaluated, 26 and stability is obtained regardless of the type of dissipation as long as the dissipation is sufficiently large. With the addition of dissipation, the "resistive wall mode" begins to rotate with the plasma, and it is the rotation of the mode with respect to the wall that provides stability. 


\section{EXPERIMENTS TO EVALUATE THE STABILIZING INFLUENCE OF A RESISTIVE WALL}

There are several experimental conditions required for a demonstration and evaluation of stabilization by a resistive wall. First, the experimental conditions must be such that the presence or absence of a wall is predicted to provide a substantial measurable change in maximum stable beta. Ideal stability calculations indicate that a conducting wall provides a large gain in the maximum stable beta in discharges with a broad current profile and low internal inductance, $\ell_{i}$, as has been shown for the simulated second stable core equilibria. ${ }^{6}$ Here $\ell_{i}=$ $(1 / \mathrm{V}) \int \mathrm{dv} \mathrm{B}_{\mathrm{P}}^{2} /\left(\mathrm{B}_{\mathrm{PA}}^{2}\right)$, where $\mathrm{B}_{\mathrm{PA}}=\mu_{0} \mathrm{I} / \mathrm{C}_{\mathrm{P}}$, and $\mathrm{CP}_{\mathrm{P}}$ is the poloidal circumference. Large beta limit differences are calculated for equilibria obtained on DIII-D. With $\ell_{i}=0.7$, the maximum beta calculated to be stable without a wall is $\beta_{\mathrm{N}}=2.8$ but the maximum beta calculated to be stable with the DIII-D wall is $\beta_{N}=4.8$. The gain in beta provided by a conducting wall is much less significant at higher $\ell_{\mathrm{i}}$. For a DIII-D discharge at $\ell_{\mathrm{i}} \approx 1.2$, the maximum stable beta without a wall was found to be $\beta_{\mathrm{N}}=3.3$; and with the inclusion of the wall, the maximum stable beta was calculated to be $\beta_{N}=3.5$. These calculations show that as $\ell_{\mathrm{i}}$ increases, the kink mode becomes more internal and therefore is less influenced by the presence of a wall. At yet higher $\ell_{i}$, the maximum stable beta is limited by high $\mathrm{n}$ ballooning modes, 13,27 and is independent of the all location. To most clearly observe the stabilizing influence of a conduction wall, low $\ell_{\mathbf{i}}, \ell_{\mathrm{i}} \lesssim 0.8$ discharges are required.

Broad pressure profiles are also optimum for evaluating the effect of wall stabilization. It is found that the stability of discharge with peaked pressure profiles in general determined by internal modes and that the presence or absence of a wall therefore does not affect the stability 
limit. In DIII-D H-mode discharges, the pressure profiles are typically quite broad, with the pressure peaking factor, $\mathrm{p}(0) /\langle\mathrm{p}\rangle \approx 2$.

The optimum plasma to wall distance for stabilization by a resistive wall is not clear. Using a wall conformal to the plasma, Bondeson et al. ${ }^{23}$ calculated a ratio of the wall to plasma separation to plasma radius of $d / a \approx 0.3$ is near the optimum. For our wall stabilization experiments, we chose to use the standard DIII-D double-null configuration with $a=0.62 \mathrm{~m}$ and the separation between the last closed flux surface and the wall at the outer midplane $d=b-a=$ $0.13 \mathrm{~m}$. This gives $d / a \approx 0.2$ at the outer midplane, but the consideration of the port openings in the wall and the fact that a larger plasma to wall separation exists away from the midplane increases the effective $d / a$

Low $\ell_{\mathrm{i}}$ was obtained in the experiments by beginning the auxiliary heating very early in the current ramp. Immediately following plasma breakdown, the current profile is typical very broad with $\ell_{\mathrm{i}} \approx 0.6$. Deuterium neutral beam injection beginning at $\mathrm{t}=0.3 \mathrm{~s}$ heats the plasma and greatly lengthens the current shear time of the plasma . An early H-mode transition further increases the edge temperature, broadening the temperature and the pressure profile, helping to maintain a low $\ell_{\mathrm{i}}$ target. Tangential beams, [tangency radius $=1.16 \mathrm{~m}\left(\mathrm{R}_{0}=1.7 \mathrm{~m}\right)$ ] are used for the early injection to maximize the toroidal momentum input and thus the rotation frequency. Additional beam power, both tangential and perpendicular (tangency radius $=0.77 \mathrm{~m}$ ) is added at a later time to increase beta. The evolution for discharge 80111 is shown in Fig. 1 . The early beam power also keeps $q(0)>1$ as shown in Fig. 1(b).

Detailed profile information was obtained throughout the discharge evolution. The electron temperature and density profiles were measured using a multi-pulse Thomson system, with a time interval between pulses of $8 \mathrm{~ms}$. Additional density data came from two vertically and one radially viewing two-color interferometers. The ion temperature and rotation profiles are 


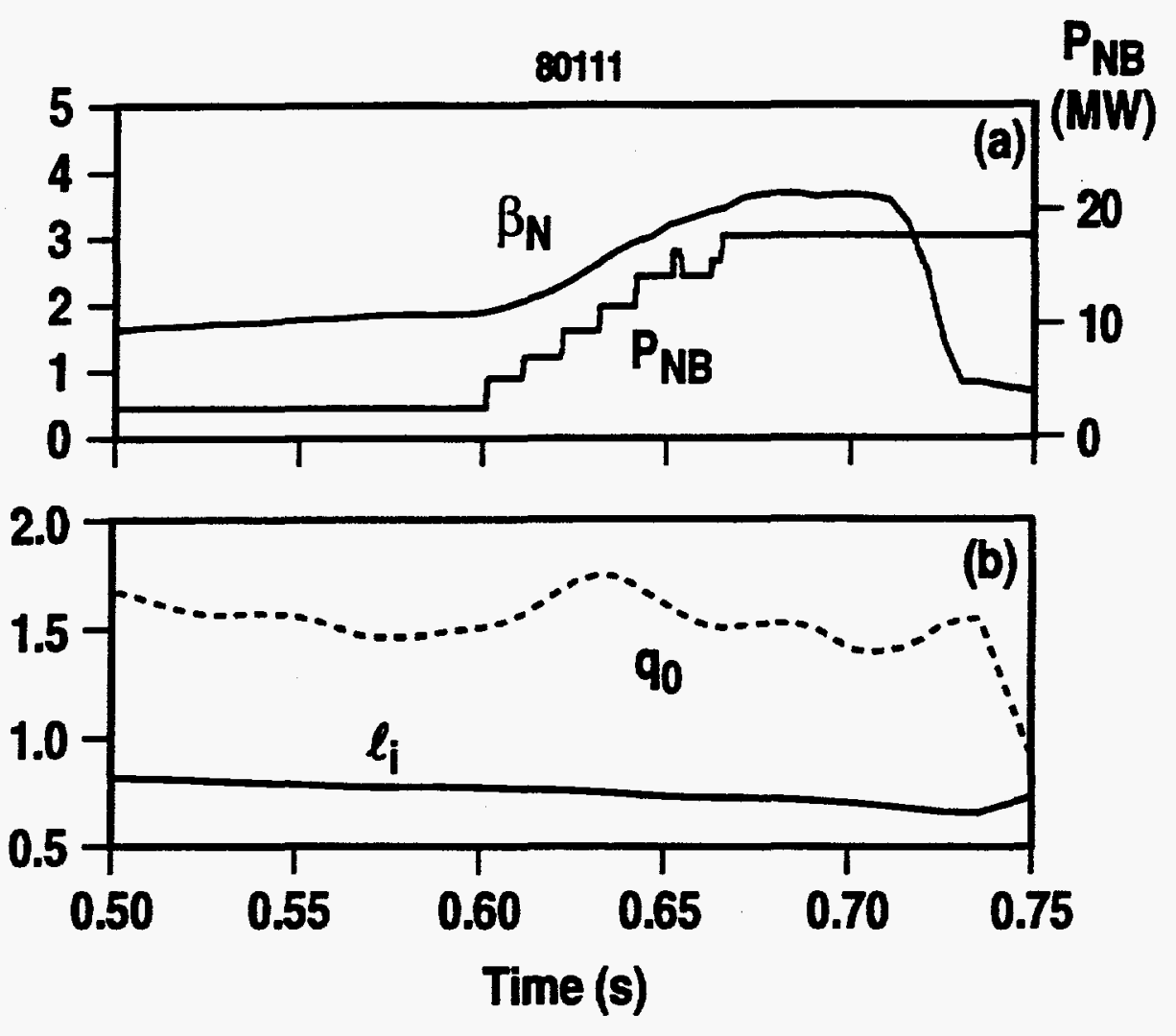

Fig.1. Temporal evolution of wall stabilized discharge. (a) normalized plasma beta, $\beta_{N}=$ $\left.\beta_{T} /(1 / a B) \%-m-T / M A\right)$, and injected neutral beam power, $P_{N B}(b)$ calculated internal inductance $\ell_{\mathrm{i}}$ and measured central safety factor, $q(0)$

measured using a 32 channel CERspectrometer, viewing a carbon impurity line. The toroidal rotation velocity of the carbon impurity is nearly identical to that of the main ion except in the very edge region of the plasma. 28 Values of toroidal rotation determined from the measured frequency of Mirnov oscillations are found to agree remarkably well with the fluid rotation, especially in the plasma core. The $\mathrm{Z}_{\mathrm{eff}}$ is determined from visible bremsstrahlung measurements along 16 tangentially viewing chords. The internal field pitch is calculated using the motional Stark effect: either an 8 or 16 chord system. The magnetic axis shift and the location of rational $q$ surfaces are determined from two poloidal arrays of soft X-ray detectors. Magnetic measurements include 40 poloidal flux loops, 50 poloidal magnetic field probes, plasma current 
Rogowskis loops, diamagnetic flux loops, and toroidal and poloidal coil current measurements. All the above data are used in the equilibrium reconstruction performed with the EFIT code. 29

A scaling of DIII-D experimental data is shown in Fig. 2. The crosses in this figure include data from the DIII-D stability data base prior to the recent wall stabilization experiments. Most discharges are heated with beam heating only during the plasma current flat top with $\ell_{\mathrm{i}}$ in the range of 1 to 2 . The high $\ell_{\mathrm{i}}$ DIII-D data, and data from other tokamaks led to a scaling of the beta limit with peaking of the current profile, $\beta_{\mathrm{N}}<4 \ell_{\mathrm{i}}{ }^{2}$ As can be seen from the solid points in Fig. 2, a number of discharges exceed the previous scaling $\beta_{N}=4 \ell_{i}$ by $40 \%$.

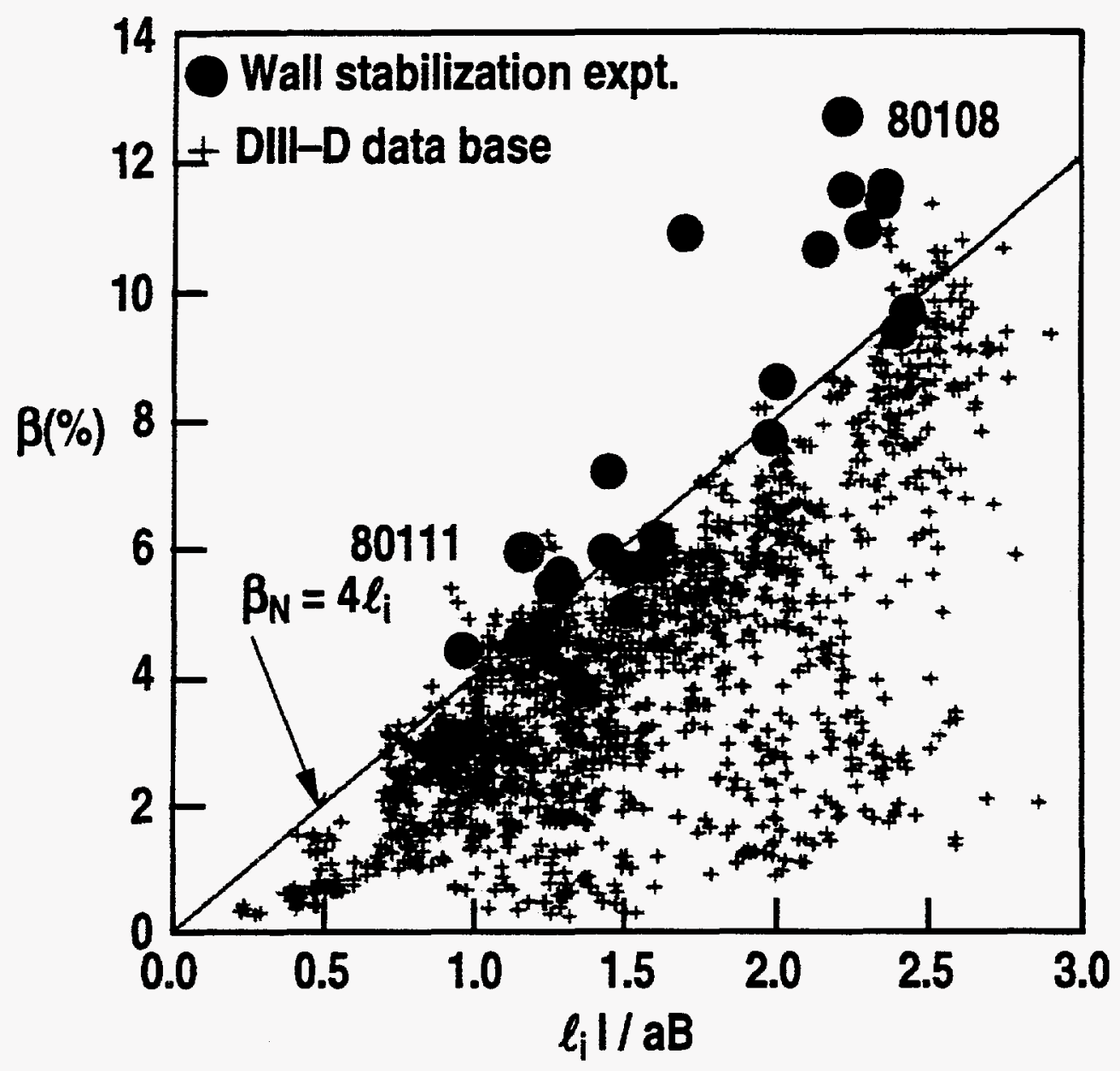

Fig. 2. Scaling of the DIII-D beta limit with $\ell_{i}$ and normalized current, including the recent high beta experiments, solid circles. 


\section{STABILITY ANALYSIS}

In order to show that a resistive wall provides stability, we first show that the plasma is unstable in the absence of a wall. Detailed equilibrium reconstruction and stability analysis has been completed for two of the discharges which significantly exceed $\beta_{N}=4 \ell_{i}$, discharge 80111 with $q(0)>1$ which reached $\beta \pm 6.1 \%, \beta_{\mathrm{N}}=3.8$, and 80108 with $q(0)<1$ which reached $\beta_{\mathrm{T}}=$ $12.6 \%, \beta_{\mathrm{N}}=4.3$. In discharge $80111, q(0)$ was intentionally maintained above unity by early beam injection during the current ramp with $q 95 \approx 6$. Maintaining $q(0)$ above unity allows unambiguous ideal stability analysis to be completed without the complication of the internal kink.

Equilibrium reconstruction utilizing all the available data was completed for five different times from $0.62 \mathrm{~s}$ to $0.705 \mathrm{~s}$ for discharge 80111 . The pressure profile is constrained by the measured thermal pressure profile and the calculated fast ion pressure. The $q$ profile is constrained by the internal field line pitch measurements from MSE. The equilibria were obtained at high resolution, ( $129 \times 129$ grid $)$ and were well converged. They were then tested for stability against the $n=1$ kink mode with the stability code GATO. 30 With no wall stabilization, the equilibria from $0.645 \mathrm{~s}$ to $0.704 \mathrm{~s}$ are all found to be unstable to a global/external kink. The equilibrium at $0.62 \mathrm{~s}$ was found to be stable without a wall. The predicted maximum stable $\beta_{\mathrm{T}}$ with no wall is found to be at $\beta_{\mathrm{T}}=4.1 \% \pm 0.2 \%, \beta_{\mathrm{N}}=2.8$. The attained maximum beta value is $\beta_{\mathrm{T}}=6.1 \% \pm 0.2 \%, \beta_{\mathrm{N}}=3.8 ; 35 \%$ higher than the ipredicted deal limit in the absence of wall stabilization. With an ideal conducting wall placed at the position of the DIII-D Inconel vessel, all the attained equilibria are stable to the $n=1$ ideal kink as shown in Fig. 3(a). By maintaining the $q$ profile approximately constant, and increasing the magnitude of the pressure, the maximum beta stable to the $n=1$ kink with an ideal wall is found to be $\beta_{N}=4.8$. 

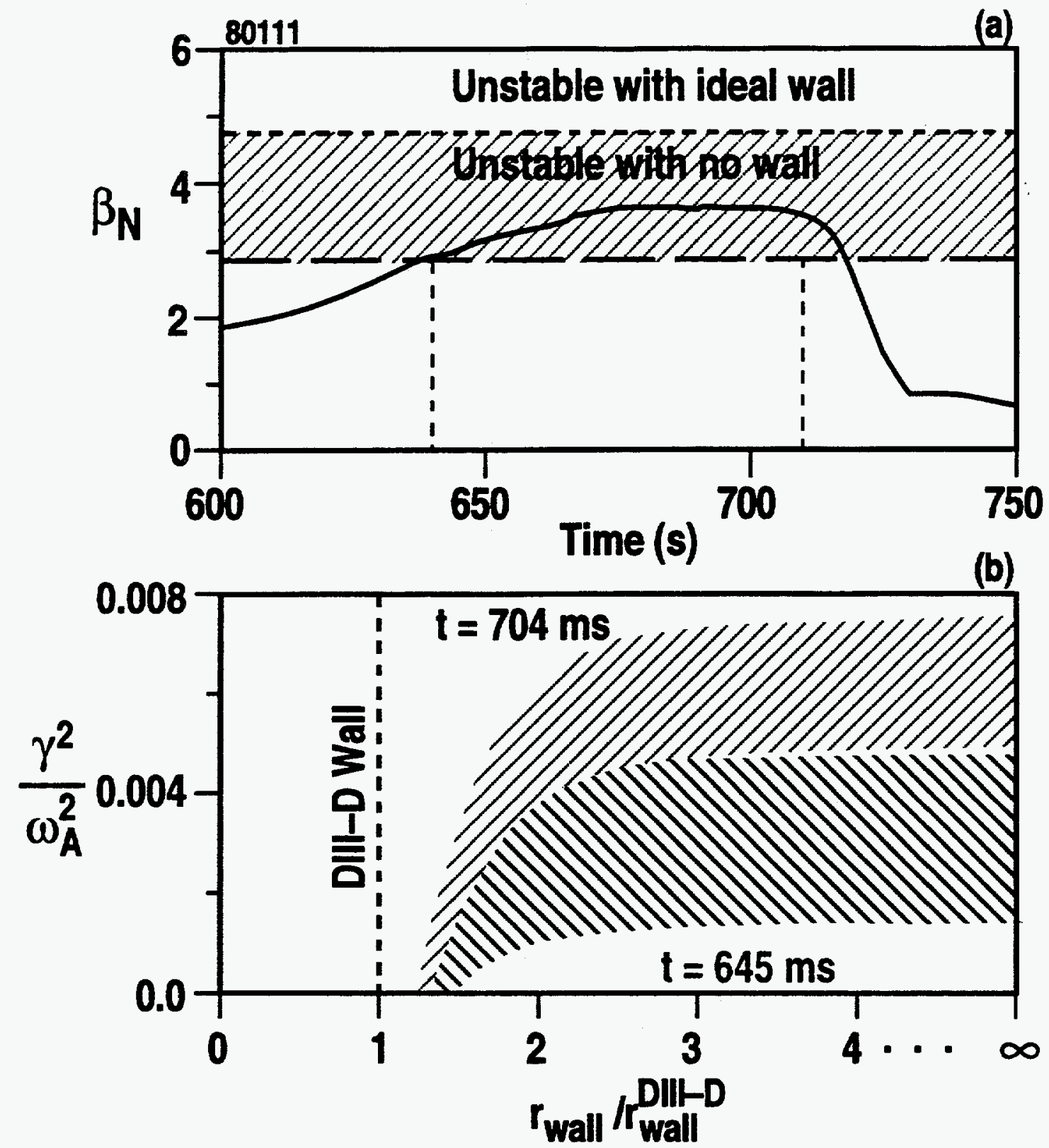

Fig. 3. Calculated ideal kink mode limits (a) normalized beta, $\beta_{N}$, dashed line is the maximum achievable beta with no wall stabilization, dotted line is the maximum achievable beta with an ideal wall and the location of the DIII-D vessel. (b) Variation of normalized growth rate, $\gamma^{2} / \omega_{A}^{2}$, with wall position for the reconstructions of discharge 80111 at $\mathrm{t}=645 \mathrm{~ms}$ and at $\mathrm{t}=704 \mathrm{~ms}$.

It is known that the stability results depend on details of the profiles, ${ }^{13}$ especially the $q$ profile. We determined that modest variations in the pressure profile did not significantly alter 
the predicted growth rate of the $n=1$ ideal kink, but that variations in the $q$ profile, especially $q(0)$ did have an impact on the predictd growth rate. Variations in the equilibria, around the best fit equilibria were generated by varying $q(0)$ within the bounds allowed by the uncertainty in the MSE data. For discharge 80111 , at $0.645 \mathrm{~s}$ the acceptable values ranged from 1.5 to 2.2 around the best fit value of $q(0)=1.65$, while at $0.704 \mathrm{~s}$ the acceptable range was 1.2 to 1.7 with the best fit at $q(0)=1.35$. Equilibria were generated with $q(0)$ over this "acceptable" range, and in some cases outside the acceptable range, and tested for ideal stability.

The conclusions of the ideal kink stability analysis do not change for the allowable variations in the equilibria. In Fig. 3(b), we show the growth rate of the $n=1$ ideal kink calculated by the stability code GATO, 30 as the radius of the wall is increased. As can be seen, at both $t=0.643$ and $t=0.704$ s., the equilibria are unstable with no wall. The growth rate does depend on the profiles, but for both cases nstability is clearly predicted over the entire range of equilibria calculated. Furthermore, the critical wall location for stability varies very little over this range of equilibria. It is important to note that decreasing $q(0)$ below the acceptable range decreased the predicted ideal growth rate. For $t=0.704 \mathrm{~s}$ the lower bound on the growth rate shown in Fig. 3(b) is for $q(0)=1.1$, for which the MSE $\chi^{2}$ increases nearly a factor of 3 over the best fit value, $q(0)=1.35$.

The highest beta discharge in DIII-D, discharge 80108, $\beta_{\mathrm{T}}=12.6 \%, \beta_{\mathrm{N}}=4.3$, is also apparently wall stabilized. This discharge has $q(0)<1$, making the interpretation of ideal stability analysis difficult because of the present of the internal $m / n=1 / 1$ kink. With no wall stabilization, the equilibrium is grossly unstable to an ideal kink with a very global structure. With an ideal wall at the DIII-D vessel location, stability analysis shows an internal kink with a smaller growth rate and a much smaller relative amplitude at the boundary suggesting that the external kink has been stabilized. The internal kink is difficult to avoid in these stability calculations. All the equilibrium reconstructions give $\mathrm{q}$ near the axis below 1 , with a minimum $q$ 
in the range $0.87<q_{\min }<0.93$. If $q(0)$ is below approximately 0.9 , the profile is monotonic, and $q(0)=q_{\min }$. Increasing $q(0)$ on axis, is acceptable, consistent with the experimental data, but then the $q$ profile becomes non-monotonic with decreasing $q^{\min }$ as $q(0)$ increases. All of these equilibria with $q^{\min }<1$ are predicted to be unstable to an ideal $\mathrm{n}=1$. To determine an upper bound on maximum stable beta with no wall it was necessary to eliminate the internal kink. We generated equilibria with a monotonic $q$ profile and $q(0)>1$ : however, these equilibria have unacceptably high fitting errors. Nonetheless, by increasing $q(0)$ to 1.05 , we were able to obtain equilibria stable to the $n=1$ ideal kink with $\beta_{N}$ up to 3.3. Decreasing $q(0)$ toward the value obtained in the experiment reduces the maximum stable beta. The experimental value is $\beta_{\mathrm{N}}^{\mathrm{EXP}}=4.3$, so we conclude that this discharge is stabilized by the resistive wall. 


\section{DISCHARGE TERMINATION AND ROTATION}

With few exceptions, all the wall stabilization experiment discharges ultimately terminated either in a disruption for the cases of $q(0) \lesssim 1$, or through a large energy collapse, for cases of $q(0)>1$. A common feature in the terminations is the appearance of a slowly growing, locked, or slowly rotating low $\mathrm{m}, \mathrm{n}=1$ mode which continued growing until discharge termination. The growth of these modes is always associated with a slowing in the plasma rotation.

The high $\beta_{\mathrm{N}}$ phase of discharge \#80111 is terminated by a slowly growing, very slowly rotating $3 / 1$ mode. During the high $\beta_{N}$ phase, the plasma rotation steadily decreased, as inferred from CER measurements and the frequencies of saturated, rotating $2 / 1$ and $5 / 2$ tearing modes [see Fig. 4(b)]. The rotation of the $q=2$ surface is slowing but remains greater than $5 \mathrm{kHz}$, sufficient to provide stabilization of the $\mathrm{m} / \mathrm{n}=2 / 1$ mode. However, the plasma rotation velocity at the $q=3$ surface, as determined from charge exchange recombination (CER) spectroscopy, decreases to zero shortly before the onset of the instability. At $711 \mathrm{~ms}$, a $3 / 1$ mode appears and grows with a $6 \mathrm{~ms}$ growth time, Fig. 4(c). By examining the slow evolution of these non-axisymmetric poloidal field fluctuations as measured by a toroidal Mirnov array, the observed 3/1 mode is found to have a rotation frequency of $25 \mathrm{~Hz}$. Both the growth rate and the real frequency are in approximate agreement with the recent theory for the resistive wall mode which includes both rotation and dissipation. The major loss of energy in 80111 , as seen from the decay in the central SXR, occurs when the $\mathrm{m} / \mathrm{n}=2 / 1$ mode appears. Although not shown for this case, we expect that the slowing of the rotation at the $q=2$ surface is the important element in the loss of $m / n=2 / 1$ stability.

The appearance of the slowly rotating 3/1 mode in discharge \#80111 is associated with the very slow rotation at the $q=3$ surface on the basis of the theory prior to 1993 which did not 


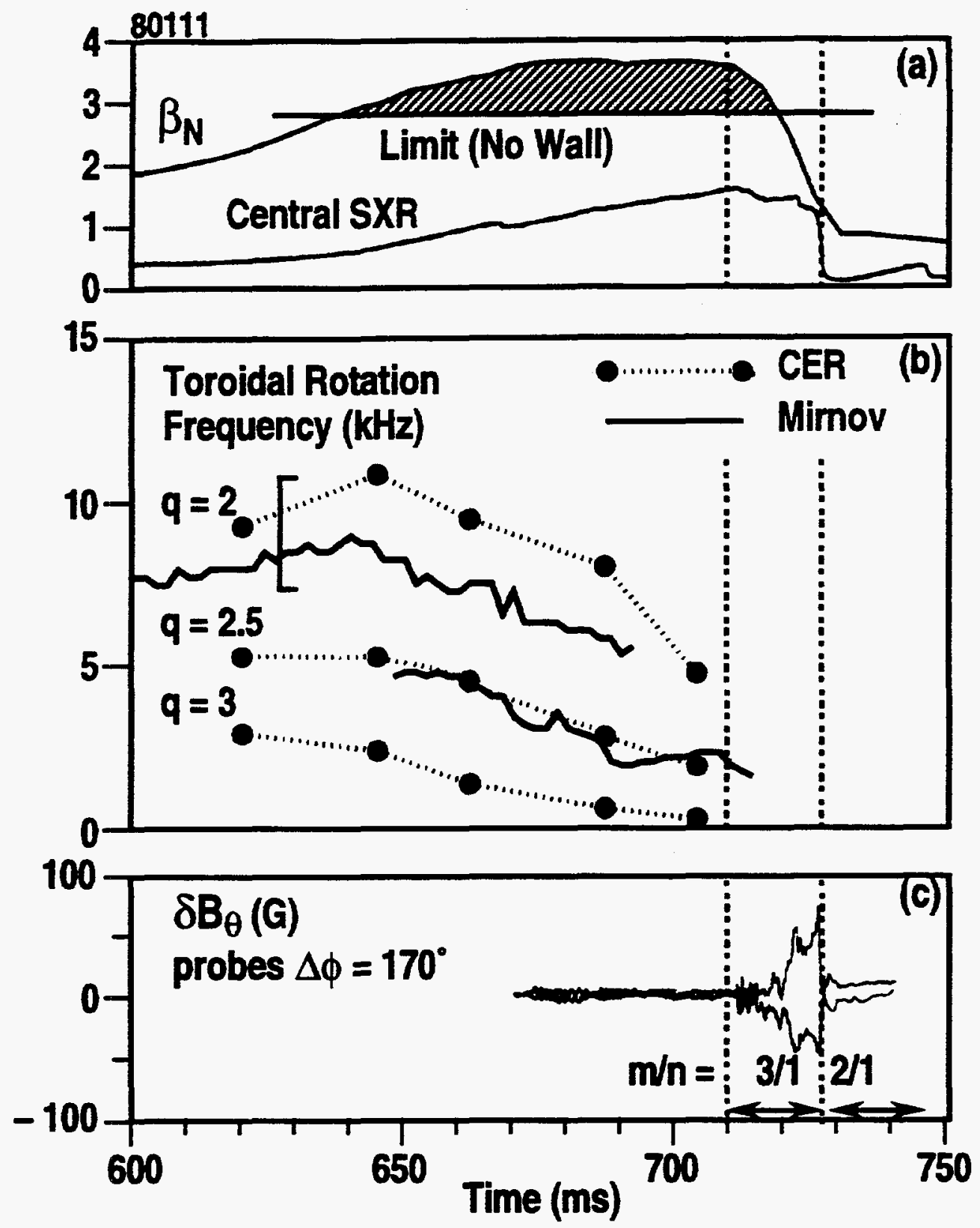

Fig. 4. The temporal evolution of discharge 80111 , showing the correlation between the rotation, and the growth of the unstable mode. (a) normalized beta, $\beta \mathrm{N}$, and central SXR, (b) toroidal rotation frequencies at several rational surfaces from magnetic (Mirnov) oscillations and CER spectroscopy; and (c) measurement of $\delta \mathrm{B}_{\theta}$ from two magnetic probes separated toroidally by $170^{\circ}$, the separation of the two signals at $t \sim 712 \mathrm{~ms}$ indicates the growth of an $n=1$ mode. 
include dissipation. Instabilities were expected to appear during the high entire $\beta_{\mathrm{N}}$ phase independent of plasma rotation; however, the mode appeared only when the rotation was approximately zero. More recent theory and numerical calculations ${ }^{19}$ now suggest that the resistive wall mode can be stabilized for a range of wall positions if there is sufficient plasma rotation. The critical magnitude of the plasma rotation depends on the details of the model, but the early calculations suggest a few percent of the Alfvén velocity or a substantial fraction of the sound speed. However, the measured rotation rate of the 3/1 surface in discharge 80111 appears to be very low before the instability appears.

To more accurately evaluate the magnitude of the rotation required for stabilization, magnetic braking by an applied non-axisymmetric field was used to systematically reduce the plasma rotation. ${ }^{26,29}$ Recently, an error field correction coil (C-coil) ${ }^{23}$ was installed on DIII-D to reduce the inherent error field produced from a very small misalignment of the poloidal field coils. The C-coil can also be used to increase the non-axisymmetric field and thus provide additional magnetic drag on the plasma. ${ }^{31,32}$ With the C-coil segments connected to produce an $\mathrm{n}=1$ field, we can produce primarily $\mathrm{m}=1,2$, and 3 poloidal harmonics, with the higher poloidal harmonics very nearly zero. The field produced by the C-coil therefore will interact with the plasma primarily at the $q=1,2$, and 3 rational surfaces and provides a momentum "drag" at these locations.

High beta discharges very similar to discharge 80111 with $q(0)$ above 1 were produced. During the high beta phase, the C-coil was energized to reduce the rotation. Since $q$ is everywhere above unity, the braking from the applied non-axisymmetric fields is localized to the $q=2$ and 3 surfaces. With increasing coil current, or increasing non-axisymmetric fields, it is found that the high beta phase terminates sooner: The temporal evolution of $\beta$ for two similar discharges with different $\mathrm{C}$-coil current is displayed in Fig. 5. On examining the toroidal 


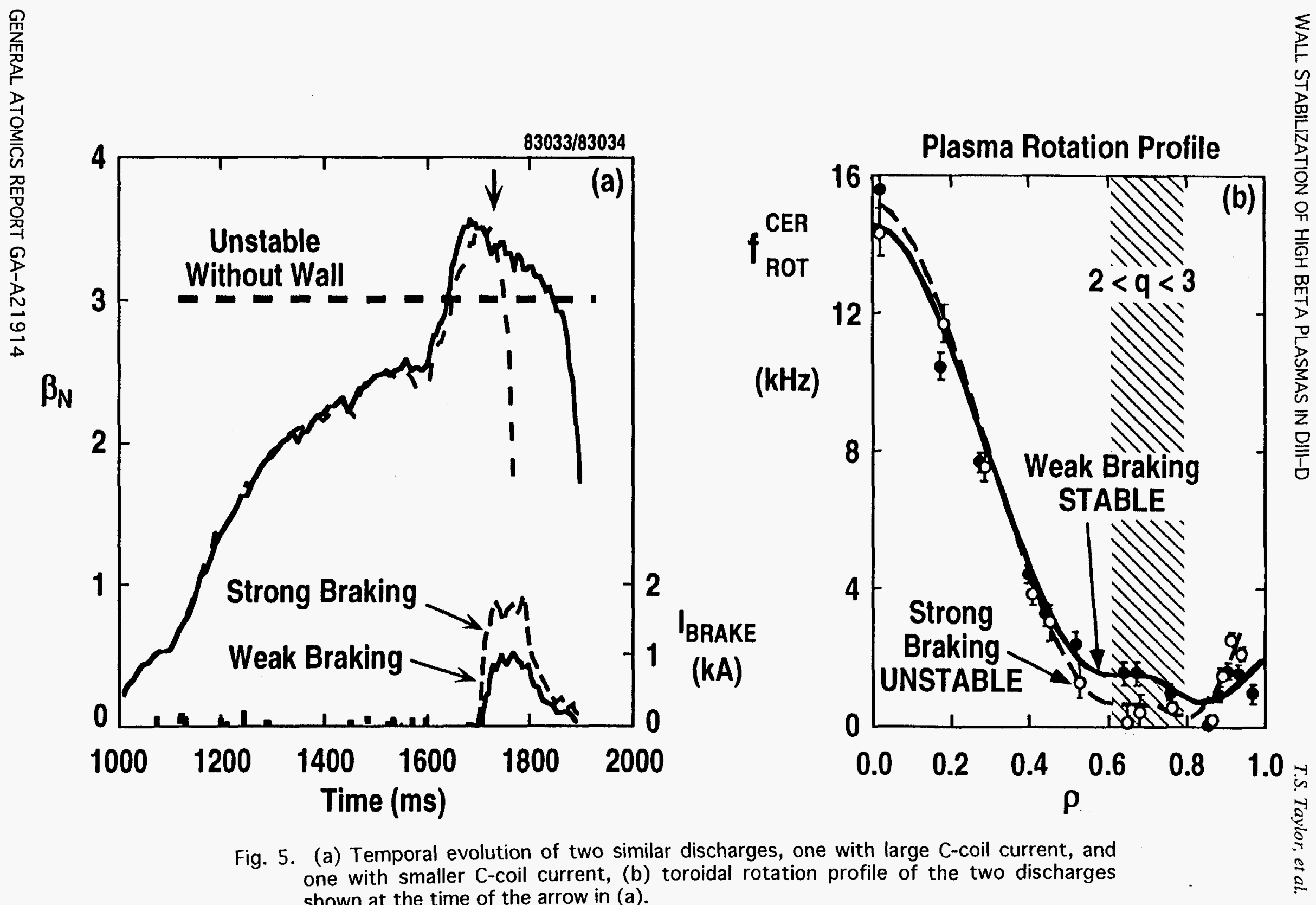


rotation profiles, it is found that although the central rotation in these discharges remains high, the rotation at the $q=2$ and 3 surfaces is greatly reduced, as shown in Fig. 5(b). When the rotation frequency near the $q=2$ and 3 surfaces is reduced below approximately $1 \mathrm{kHz}$, an unstable $n=1$ mode is observed to grow and limit beta. It is important to note that the rotation outside of the $q=2$ and 3 surfaces continues as a consequence of the nature of the local interaction between the fields from the coil and the plasma, but it appears to be the rotation near the $q=2$ and 3 surfaces that is important for influencing stability kink [see Fig. 5(b)].

This experiment suggests that the rotation near the low order rational surfaces ( $q=2$ and 3 ) is important and that the critical rotation speed of these surfaces is near $\Omega / 2 \pi=1 \mathrm{kHz}$. This rotation speed is significantly lower than the expected critical rotation speed from many of the theoretical predictions. But, recent numerical calculations by Chu using the MARs code indicate much slower rotation than originally expected appears to suffice for these highly shaped DIII-D equilibria in the presence of large perpendicular viscosity. 26 



\section{DISCUSSION}

These recent experiments with detailed profile measurements indicate that the DIII-D high beta discharges are wall stabilized. The experimental beta values achieved exceed by greater than $30 \%$ those values predicted by the ideal calculations with no wall stabilization. This result is insensitive to variations in the range of possible equilibria consistent with the experiment measurements. The unstable modes, which are observed when the rotation velocity becomes too small, have both a growth rate and a real rotation frequency that is consistent with recent theoretical predictions.

Rotation is a key essential feature necessary for wall stabilization to occur. The onset of the unstable "resistive wall mode" occurs when the rotation of the outer low order rational surfaces decreases below a critical value. The critical rotation speed is significantly lower than originally expected, near $\Omega / 2 \pi=1 \mathrm{kHz}$. A significant amount of additional research, both experimental and theoretical, remains to be completed to develop an understanding of the required rotation speed as a function of plasma properties and profiles. Theoretically, the rotation speed required depends critically on the magnitude of the dissipation. Precise models for the plasma dissipation remain to be established.

High beta wall stabilized discharges have not yet been obtained in steady state. Maintaining the plasma rotation at high beta clearly remains a challenge. There are a number of known causes leading to the plasma slowing down: non axisymmetric error fields, saturated tearing modes, loss of momentum input as a consequence of Alfvén eigenmodes and edge localized modes (ELMs). Ways to avoid some of these angular momentum losses are known. For example, we are confident that the error fields can be reduced by appropriately designed compensation coils and that the tearing modes can be eliminated by small modifications in the 
current density profile. We also expect that for moderate $q$ discharges, ELMs would contribute primarily to slowing the rotation at the edge and not significantly reduce the rotation near the $q=$ 2 and 3 surfaces. However, at lower values of edge $q$, ELMs might remain a concern. Innovative ideas of how to robustly maintain the plasma rotation clearly can have a large impact on the realizable plasma beta.

The validation of stabilization of the external kink by a resistive wall in the presence of plasma rotation removes a long standing discrepancy between the theoretical predictions of the beta limit and the experimentally obtained beta values. With resistive wall stabilization of the external kink, a credible path toward the simultaneous achievement of high beta and good confinement, in self-consistent steady-state high bootstrap fraction discharges emerges as have been predicted for future work in DIII-D ${ }^{33}$ and the planned Tokamak Physics Experiment (TPX). 34 


\section{REFERENCES}

${ }^{1}$ J.L. Luxon, R. Anderson, F. Batty, C.B. Baxi, G. Bramson, N.H. Brooks, B. Brown, B. Burley, K.H. Burrell, R. Callis, G. Campbell, T.N. Carlstrom, A.P. Colleraine, J. Cummings, L. Davis, J.C. DeBoo, S. Ejima, R. Evanko, H. Fukumoto, R. Gallix, J. Gilleland, T. Glad, P. Gohil, A. Gootgeld, R.J. Groebner, S. Hanai, J. Haskovec, E. Heckman, M. Heilberger, F.J. Helton, N. Hosogane, C.-L. Hsieh, G.L. Jackson, G. Jahns, G. Janeschitz, E. Johnson, A.G. Kellman, J.S. Kim, J. Kohli, A. Langhorn, L.L. Lao, P. Leek, S. Lightner, J. Lohr, M.A. Mahdavi, M. Mayberry, B. McHarg, T. McKelvey, R. Miller, C.P. Moeller, D. Moore, A. Nerem, P. Noll, T. Ohkawa, N. Ohyabu, T.H. Osborne, D.O. Overskei, P.I. Petersen, T.W. Petrie, J. Phillips, R. Prater, J. Rawls, E.E. Reis, D. Remsen, P. Riedy, P. Rock, K. Schaubel, D.P. Schissel, J.T. Scoville, R. Seraydarian, M. Shimada, T. Shoji, B. Sleaford, J.P. Smith, Jr., T. Smith, R.T> Snider, R,D. Stambaugh, R. Stav, H. St. John, R.E. Stockdale, E.J. Strait, R. Stree, T.S. Taylor, J. Tooker, M. Tupper, S.K. Wong and S. Yamaguchi, Plasma Phys. and Contr. Nucl. Fusion Research, 1986 (International Atomic Energy Agency, Vienna, 1987), Vol. I, p. 159.

2E.J. Strait, Phys. Plasmas 1, 1415 (1994).

${ }^{3}$ F. Troyon, R. Gruber, H. Sauernmann, S. Semenzato, S. Succi, Plasma Phys. and Contr. Fusion 26, 209 (1984).

4J.D. Galambos, S. Haney, L.J. Perkins, J. Mandrekas, "The Impact of Improved Physics on Commercial Tokamak Reactors," ORNL Ridge National Laboratory Report ORNL/TN 12483 (1994) submitted to Nucl. Fusion

5P.N. Yushmanov, T. Tkizuka, K.S. Riedel, O.J.W.F. Kardaun, J.G. Cordey, S.M. Kaye, D.E. Post, Nucl. Fusion 30, 1999 (1990). 
${ }^{6}$ A.D. Turnbull, T.S. Taylor, E.J. Strait, S.J. Thompson, M.S. Chu, J.R. Ferron, L.L. Lao, B.W. Rice, O. Sauter, R.T. Snider, D. Wroblewski, Phys. Rev. Lett. 74, 718 (1995).

7 C. Kessel, Phys. Rev. Lett. 72, 1212 (1994); J. Manickam, M.S. Chance, S.C. Jardin, C. Kessel, D. Monticello, N. Pomphrey, A. Reiman, C. Wang, L.E. Zakharov, Phys. Plasmas 1, 1601 (1994).

${ }^{8}$ K. Bol, D. Buchenauer, M. Chance, P. Couture, Phys Rev. Lett. 57, 1891 (1986).

${ }^{9}$ M. Okabayashi, K. Bol, M. Chance, P. Couture, H. Fishman, R.J. Fonck, G. Gammel, W.W. Heidbrink, K. Ida, K.P. Jaehnig G. Jahns, R. Kaita, S.M. Kaye, H Kugel, B. LeBlanc, J. M ickam, W. Morris, G.A. Navratil, N. Ohyabu, S. Paul, E. Powell, M. Reusch, S. Sesnic, H. Takahashi, Plasma Phys. and Contr. Nucl. Fusion Research 1986 (Proc. 11th Int. Conf, Tokyo, 1986) International Atomic Energy Agency, Vienna, 1987 Vol. I, p. 275.

${ }^{10}$ E.J. Strait, L.L. Lao, T.S. Taylor, M.S. Chu, J.K. Lee, A.D. Turnbull, S.L. Allen, N.H. Brooks, K.H. Burrell, R.W. Callis, T.N. Carlstrom, M.S. Chance, A.P. Colleraine, D. Content, J.C. DeBoo, J.R. Ferron, J.M. Greene, R.J. Groebner, W.W. Heidbrink, F.J. Helton, D.N. Hill, R.-M. Hong, N. Hosogane, W. Howl, C.L. Hsieh, G.L. Jackson, G.L. Jahns, A.G. Kellman, J. Kim, S. Kinoshita, E.A. Lazarus, P.J. Lomas, J.L. Luxon, M.A. Mahdavi, Y. Neyatani, T. Ohkawa, T.H. Osborne, D.O. Overskei, T. Ozeki, M. Perry, P.I. Petersen, T.W. Petrie, J.C. Phillips, G.D. Porter, D.P. Schissel, J.T. Scoville, R.P. Seraydarian, M. Shimada, T.C. Simonen, R.T. Snider, R.D. Stambaugh, R.D. Stav, H. St. John, R.E. Stockdale, U. Stroth, R.Wood, Plasma Phys. and Contr. Nucl. Fusion Research 1988, (Proc. 12th Int. Conf., Nice, 1988) International Atomic Energy Agency, Vienna, 1989 Vol. I, p. 83.

${ }^{11}$ L.L. Lao, Phys Fluids B 4, 232 (1992).

12T.S. Taylor, E.A. Lazarus, M.S. Chu, J.R. Ferron, F.J. Helton, W. How., G.L. Jackson, T.H. Jensen, Y. Kamada, A.G. Kellman, L.L. Lao, R.J. La Haye, J.A. Leuer, J.B. Lister, T.H. Osborne, R.T. Snider, R.D. Stambaugh, E.J. Strait, A.D. Turnbull, Plasma Phys. and Contr. 
Nucl. Fusion Research 1990 Washington (International Atomic Energy Agency, Vienna, 1991) Vol. 1, p 177.

13W.W. Howl, A.D. Turnbull, T.S. Taylor, L.L. Lao, J.L. Helton, J.R. Ferron, E.J. Strait, Phys. Fluids B 4, 1724 (1992).

${ }^{14}$ L. Zakharov and S.V. Putvinskii, Sov. J. Plasma Phys. 13, 68 (1987).

15J.P. Freidberg, Ideal Magnetohydrodynamics (Plenum Press, New York, 1987).

16D. Pfirsch, and H. Tasso, Nucl. Fusion 11, 259 (1971).

${ }^{17}$ S. W. Haney and J. P. Freidberg, Phys Fluids B 1, 1637 (1989).

${ }^{18}$ E.J. Strait, T.S. Taylor, A.D. Turnbull, J.R. Ferron, L.L. Lao, B.W. Rice, O. Sauter, S.J. Thompson, D. Wroblewski, "Wall Stabilization of High Beta Tokamak Discharges in DIII-D," submitted to Phys. Rev. Lett.

${ }^{19}$ A.D. Turnbull, T.S. Taylor, E.J. Strait, S.J. Thompson, M.S. Chu, J.R. Ferron R.J. La Haye, L.L. Lao, R.T. Snider, B.W. Rice, D. Wroblewski, O. Sauter, M.E. Mauel, A. Popov, N. Popova, D.J. Lightly, J.D. Williams, "Wall Stabilization of Rotating High $\beta$ Discharges in DIII-D," Plasma Physics and Controlled Nuclear Fusion Research 1994 (International Atomic Energy Agency, Seville) to be published.

${ }^{20}$ E.J. Strait, T.S. Taylor, A.D. Turnbull, J.R. Ferron, L.L. Lao, "Wall Stabilization Effects in DII-D High Beta Discharges," in Proceedings of 21st European Conference on Controlled Fusion and Plasma Physics, Montpellier, France 1994 (European Physical Society, PetitLancy, Switzerland, 1994) Vol. 18B, p. 242.

${ }^{21}$ D. Wroblewski, L.L. Lao, Rev. Sci. Instrum. 63, 5140 (1993).

22P. Gohil, K.H. Burrell, R.J. Groebner, J, Kim, W.C. Martin, E.L. McKee, R.P. Seraydarian, in Proceedings of the 14th IEEE/NPSS Symposium on Fusion Engineering, San Diego, California, 1991 (Institute of Electrical and Electronics Engineers, Inc., 1992) Vol. 2, p. 1199. 
23J.T. Scoville, and R.J. La Haye, in Proceedings of the 14th IEEE/NPSS Symposium on Fusion Engineering, San Diego, California 1991 (Institute of Electrical and Electronics Engineers, Inc., 1992) Vol. 2 , p. 1145.

${ }^{24}$ A. Bondeson, and D.J. Ward, Phys. Rev. Lett. 72, 2709 (1993).

${ }^{25}$ D.J. Ward and A. Bondeson, "Wall Stabilization of Ideal Modes in Tokamaks," to be published in Plasma Physics and Controlled Nuclear Fusion, (Proceedings of $15^{\text {th }}$ Int. Conf., Seville).

${ }^{26}$ M. Chu, J. Greene, W. Ling, A.D. Turnbull, H.L. Berk, and M.N. Rosenbluth, Phys. Plasmas 1, 1214 (1994).

27J.R. Ferron, L.L. Lao, T.S. Taylor, Y.B. Kim, E.J. Strait, and D. Wroblewski, Phys. Fluids B 5, 2532 (1993).

28J. Kim, et al., Phys. Rev. Lett. 72, 2199(1994).

${ }^{29}$ L.L. Lao, J.R. Ferron, R.J. Groebner, W. Howl, H. St. John, E.J. Strait, and T.S. Taylor, Nucl. Fusion 30, 1035 (1990).

30L.C. Bernard, F.J. Helton, R.W. Moore, Comput Phys. Commun. 24, 377 (1981).

31R.J. La Haye, A.W. Hyatt, and J.T. Scoville, Nucl. Fusion 32, 2119 (1992).

32R.J. La Haye, C.L. Rettig, R.J. Groebner, A.W. Hyatt and J.T. Scoville, Phys. Plasmas 1, 373 (1994).

33T.S. Taylor, H. St. John, A.D. Turnbull, Y.R. Lin-Liu, K.H. Burrell, V. Chan, M.S. Chu, J.R. Ferron, L.L. Lao, R.J. La Haye, E.A. Lazarus, R.L. Miller, P.A. Politzer, D.P. Schissel, E.J. Strait, "Optimized Profiles for Improved Confinement and Stability in the DIII-D Tokamak," General Atomics Report GA-A21757, to be published in Plasma Phys. and Contr. Fusion.

${ }^{34}$ R.J. Goldston, G.H. Neilson, K.I. Thomassen, D.B. Batchelor, P.T. Bonoli, J.N. Brooks, R. Bulmer, M.E. Fenstermacher, D.N. Hill, A. Hubbard, E.F. Jaeger, S. Jardin, C. Kessel, R.J. La Haye, S.L. Liew, J. Manickam, T.K. Mau, D. Mikkelsen, P. Moroz, W.M. Nevens, L.D. Pearlstein, L.J. Perkins, P.A. Politzer, N. Pomphrey, M. Porkolab, J. Ramos, W.T. Reiersen, 
A. Reiman, C. Rewoldt, T.D. Ronglien, D.N. Ruzic, J.E. Scharer, J.A. Schmidt, J.C. Sinnis, D.P. Stottler, W. Tang, M. Ulricdkson, C. Wang, K.A. Werley, G. Wurden, L. Zakharov, Controlled Fusion and Plasma Physics (Proc. 20th Euro. Conf., Lisboa, 1993) European Physical Society, Petit-Lancy, Switzerland, 1993, Vol 17C, Part I, p. 319. 



\section{ACKNOWLEDGMENTS}

The excellent operation and performance of the DIII-D heating systems and diagnostic systems was crucial to the completion of this work. The authors would like to thank V. Chan for his strong support of this effort, and the encouragement received from the TPX physics team, especially R. Goldston. We would like to thank R. Fitzpatrick for the encouragement to use the external non-axisymmetric field to control the rotation and his help with understanding Eq. (1). This is a report of research supported by the U.S. Department of Energy under Contract Nos. DE-AC03-89ER51114, DE-AC05-84OR21400, and W-7405-ENG-48. 